\title{
Deciphering the role of AMPK-related kinase 5 in human cancer progression and metastasis
}

\author{
Alfredo Bambang ${ }^{1}$, Caroline Tanadi ${ }^{2}$, Anton Sumarpo ${ }^{1, *(1)}$
}

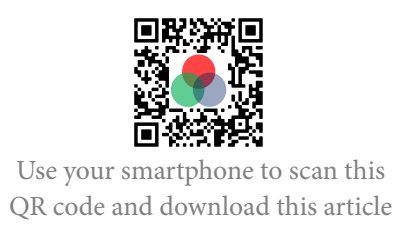

${ }^{1}$ Department of Chemistry and Biochemistry, School of Medicine and Health Sciences, Atma Jaya Catholic University of Indonesia, Jakarta, 14440, Indonesia

${ }^{2}$ Undergraduate Medical Program, School of Medicine and Health Sciences, Atma Jaya Catholic University of Indonesia, Jakarta 14440, Indonesia

\section{Correspondence}

Anton Sumarpo, Department of Chemistry and Biochemistry, School of Medicine and Health Sciences, Atma Jaya Catholic University of Indonesia, Jakarta, 14440, Indonesia

Email: anton.sumarpo@atmajaya.ac.id

History

- Received: Jun 06, 2019

- Accepted: Sep 23, 2019

- Published: Oct 24, 2019

DOI :

https://doi.org/10.15419/bmrat.v6i10.568

\section{Check for updates}

\section{Copyright}

(c) Biomedpress. This is an openaccess article distributed under the terms of the Creative Commons Attribution 4.0 International license.

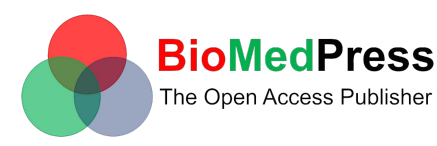

\begin{abstract}
Malignancies related mortality is currently growing at an alarming rate. Early detection of cancer is vital in order to improve survival rates of cancer patients, and biomarker detection is regarded as one of the most promising approaches. Recent studies have reported that elevated ARK5 expression is associated with tumor progression and metastasis in several human malignancies. Several pathways are also influenced by the presence of ARK5, most notably the PI3k-Akt pathway, m-TOR phosphorylation, and several pathways that induce increased tumor invasion activity. Additionally, ARK5 expression are linked to miR-1181 down-regulation, which promotes epithelial mesenchymal transformation in ovarian cancer cells. Furthermore, ARK5 gene transcription is also affected by the interaction of C-MAF and MAFB with both MARE core sequences present in the ARK5 promoter. Based on the current evidences, ARK5 might be the master regulator of cancer progression and metastasis, which could potentially serve as a novel target for cancer therapies.
\end{abstract}

Key words: ARK5, biomarker, cancer, epigenetics, invasion, tumor proliferation

\section{INTRODUCTION}

Noncommunicable diseases (NCDs) are the largest contributor to mortality in the world and its prevalence is growing at an alarming rate in the developing countries ${ }^{1}$. Cancer is currently regarded as one of the most important NCDs as the number of its occurrences and burden are expected to rise rapidly by the year 2030, in line with the growth of aging population worldwide $e^{2,3}$. The rise in cancer incidences and mortality is attributed to the shift in the prevalence and distribution of several risk factors associated with cancer due to socioeconomic development across the world ${ }^{4}$.

According to the status report on global cancer burden from GLOBOCAN 2018, in 2018, there were 18.1 million new cases (17.0 million excluding nonmelanoma skin cancer) and 9.6 million cancer-related deaths (9.5 million excluding non-melanoma skin cancer) worldwide ${ }^{5}$. Furthermore, nearly half of cancer mortality across the globe occur in Asia, as the majority of global population resides there, followed by Europe and America for the incidence $(23.4 \%$ and $21 \%$ of total cancer cases respectively) and mortality $(20.3 \% \text { and } 14.4 \% \text { respectively })^{5}$.

Early detection of cancer is an important order to increase the survival rate of cancer patients. Currently, cancer biomarkers detection is regarded as one of the most promising approaches. Cancer biomarkers comprise of a wide range of biochemical entities that can be used for risk assessment, diagnosis, prognosis, and monitoring of disease progression, regression and recurrence ${ }^{6}$. Unfortunately, no biomarker has been considered as an ideal cancer screening tool; thus, more studies are needed to discover new cancer biomarkers for efficient cancer diagnosis and monitoring.

Altered expression of unique proteins is one of the most promising cancer biomarkers, which are often produced by cancer cells or by other cells in response to cancer. One of them is the AMP-activated protein kinase (AMPK) family ${ }^{7-9}$. The AMP-activated protein kinase (AMPK) family consists of 13 proteins that are further divided into five subfamilies: AMP-activated protein kinase (AMPK), salt-induced kinase (SIK), microtubule-affinity-regulating kinase (MARK), brain-specific kinase (BRSK), and SNF1like kinase 1 (NUAK). These proteins are essential in several cellular activities, such as metabolism, polarity, cell proliferation or cell death, probably in a subfamily specific manner ${ }^{10-12}$.

\section{AMPK-RELATED KINASE 5 (ARK5) STRUCTURE AND FUNCTIONS}

AMPKs are a group of metabolite-sensing serine/threonine protein kinases that are activated by an increased AMP:ATP ratio in the cell during metabolic stress ${ }^{13}$. It is frequently activated in hypoxic conditions and plays a vital role in protecting cells from 


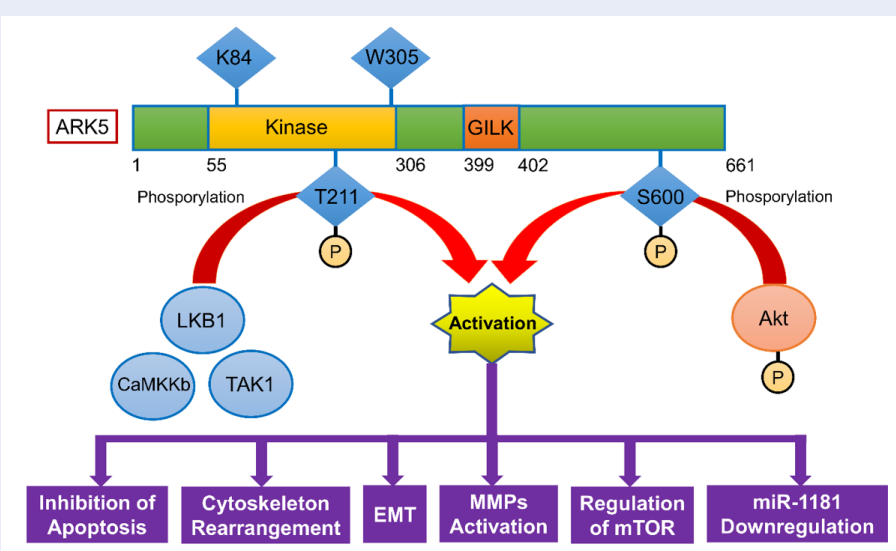

Figure 1: ARK5 sequence and pathways affected by its activation. ARK5 can be activated by the phosphorylation of either Ser- 600 by Akt or Thr-211 by LKB1, CaMKKb, or TAK1. Over-expression of ARK5 can influence several pathways that induce increased tumor proliferation and invasion, most notably the PI3k-Akt pathway, $\mathrm{m}$ TOR phosphorylation and EMT. Furthermore, ARK5 expression are associated with decreased miR-1181 expression which induces es epithelial mesenchymal transformation in ovarian cancer cells.

apoptosis by inducing changes in energy metabolism through the phosphorylation and inhibition of acetylcoenzyme A (CoA) carboxylase (ACC), and the stimulation of glucose transporters ${ }^{14,15}$.

Lately, a novel AMPK family member, Novel (NUA) kinase family 1 (NUAK1) or more commonly addressed as ARK5 was identified and found to be involved in Akt dependent cancer cell survival and migration during glucose starvation in human colon and pancreatic cancer cell lines ${ }^{16}$. The analysis of ARK5 amino acid sequence found $47,45.8,42.4$, and $55 \%$ homology to other known members of AMPK family (AMPK- $\alpha 1$, AMPK- $\alpha 2$, MELK, and SNARK, respectively), denoting that it is a member of the AMPK family ${ }^{16}$.

Human ARK5 gene, also known as KIAA0537, is located on chromosome $12 \mathrm{q} 23.3$ and consists of seven exons, approximately $76.7 \mathrm{kbp}$ of genomic DNA. It encodes a 6828-bp mRNA with four splice variants ${ }^{17}$ - ARK5 protein comprises of 661 amino acids and has a molecular mass of approximately $74 \mathrm{kDa}^{18}$. The latest evidence showed that ARK5 could also be found in the cytoplasm and imported into the nucleus by importin- $\beta$ members. Additionally, it is found that ARK5 might accumulate in the cytoplasm due to increased oxidative stress, which may impair the nuclear import process ${ }^{19}$. ARK5 consists of the putative consensus catalytic peptide sequence at amino acids 55 - 305, an Akt-phosphorylation site at Ser-600 near the C-terminus, and a conserved serine/threonine protein kinase domain in the $\mathrm{N}$ terminus (Figure 1) ${ }^{20}$. Comparing to other AMPK related kinases, ARK5 can be activated by LKB1 via the phosphorylation of Thr-211 in the T loop of the catalytic domain ${ }^{21}$. ARK5 is stimulated by increased AMP:ATP ratio and phosphorylates SAMS peptide $^{16,22,23}$. Several factors, such as insulin or insulin-like growth factor 1 (IGF1) could also activate ARK5 in a downstream manner ${ }^{16,22,23}$.

Numerous studies have reported that elevated ARK5 expression is associated with tumor progression and metastasis in several human malignancies, such as breast, colorectal, gastric, glioma, pancreatic, hepatocellular carcinomas, head and neck cancers, melanomas, nasopharyngeal, non-small cell lung cancer, ovarian and T-cell lymphomas ${ }^{24-27}$. The list of studies describing the role of ARK5 in several cancer pathways are summarized in Table 1. The pathways involved in the pathogenesis of those malignancies varied substantially and are not fully elucidated.

\section{ROLE OF ARK5 IN PI3K/AKT PATHWAY}

Akt pathway plays an important role in tumor malignancy, and it is well established that the PI3K pathway regulates Akt activity ${ }^{28}$. Suzuki et al. demonstrated that overexpression of endogenous ARK5 showed strong Akt-mediated activity and increased invasion activity in matrigel assays ${ }^{29}$. Currently, ARK5 is the only known Akt-direct downstream factor in the AMPK family. It is postulated that Akt is activated by phosphorylation of threonine 308 and serine 473 , which will then phosphorylate ARK5 at Ser600 and 
inhibit apoptosis and induces invasion activity as a consequence $^{24}$.

Activated Akt also exhibits anti-apoptotic properties by phosphorylating several apoptosis-associated factors, such as Bad, caspase 9, and forkhead, which further accentuates the problem ${ }^{30}$. Cheng et al. found that the Akt pathway was involved in mTOR/p70S6k signaling pathway, which is crucial in epithelial mesenchymal transformation (EMT) ${ }^{31}$. Furthermore, Chen et al. also provided an evidence of ARK5 involvement in Akt/mTOR/p70S6k signaling pathway, which induced invasion and metastasis of gastric cancer $^{32}$.

\section{ARK5 AND THE REGULATION OF CELL DEATH PATHWAY}

Several studies indicated that some cancer cells have high tolerance to nutrient starvation during hypoxia $^{33}$. This ability is commonly addressed as austerity and was found to be an important factor in cancer cell survival and tumor formation. Interestingly, altered ARK5 expression seems to play a central role in the development of austerity ${ }^{34}$.

A study done by Suzuki et al. (2004) discovered that overexpression of ARK5 in tumors is correlated with a significant reduction in the ratio of necrotic cell death and a significant increase in invasion activity ${ }^{29}$. It is postulated that these effects are caused by the inhibition of caspase- 8 and negative regulation of caspase-6-associated FasL/Fas system ${ }^{22}$. These findings matched the results of previous studies that observed an increased tolerance against apoptosis by glucose starvation as a consequence of inhibition of caspase 8 activation due to the preservation of $\mathrm{c}$ Flip $^{22,35}$.

\section{LKB1/ARK5 PATHWAY}

Most of AMPKs, as well as ARK5, are activated by an upstream kinase, which phosphorylates the threonine residue in the catalytic domain ${ }^{36}$. Until recently, three upstream kinases have been identified, including Liver Kinase B1 (LKB1), $\mathrm{Ca}^{2+} /$ calmodulin-dependent protein kinase kinase b (CaMKKb), and transforming growth factor-bactivated kinase 1 (TAK1) ${ }^{37,38}$. Currently, LKB1 is regarded as an essential AMPK upstream kinase ${ }^{39}$.

Although ARK5 is commonly associated with cancer cell survival and invasion, a study done by Hou et al. found that ARK5 directly phosphorylates p53 in the presence of LKB1, which in turns induces cell cycle arrest at G1 phase and exhibits tumor suppression properties ${ }^{40}$. Similar to these findings, a recent study also reported the role of ARK5 in the control of cellular senescence and ploidy, indicating the tumor suppressive properties of ARK $5^{41}$. Hou et al. observed that LKB1/ARK5 activity induces cell cycle arrest by upregulating $\mathrm{p} 21 / \mathrm{WAF}$ expression. It can be postulated that LKB1 and ARK5 form a complex with p53 in the nucleus, and binds to the p21/WAF promoter, which stimulates gene expression and leads to cell cycle arrest $^{40}$.

\section{ARK5 AND MTOR PATHWAY}

Some cancer progression was influenced by the mTOR pathway such as gastric cancer, glioma and non-small cell lung carcinoma (NSCLC) ${ }^{42}$. Suzuki et al. (2004) and Lu et al. (2013) observed that mTOR phosphorylation induced by IGF-1 is regulated by ARK5 downstream of Akt pathway ${ }^{29,43}$. Contradictory to these findings, the phosphorylation site of mTOR (Ser2448) is not compatible with AMPK family phosphorylation motif. Hence, it is reasonable that ARK5 regulates several factors associated with mTOR phosphorylation or it could phosphorylate mTOR directly at a site other than Ser2448, which in turn causes a conformational change that grants the ability to phosphorylate Ser $244^{29}$. A recent study by Chen et al. (2017) revealed that ARK5 could directly phosphorylate p70S6k and induces the downregulation of $\mathrm{mTOR}^{32}$.

\section{ARK5 AND INCREASED TUMOR INVASIVENESS}

ARK5 overexpression is related to increased tumor invasiveness in several cancer cell lines. Several studies have shown that ARK5 was significantly associated with several cancer pathways that are vital in the development of tumor invasion. These pathways include cytoskeleton rearrangement, EMT, and the activation of several matrix metalloproteinases (MMP) ${ }^{32,43,44}$. Cytoskeleton rearrangement was one of the hallmarks of increased tumor invasion activity. Previously, it was found that phosphorylation of the cofilin at Ser3 by LIM kinase 1 (LIMK1) could affect F-actin activity, and in turn, increased invasion activity and chemotaxis ${ }^{45}$. The results of a study done by Lu et al. suggested that ARK5 could interact with LIMK1 directly, and the knockdown of ARK5 resulted in decreased phosphorylation of LIMK1. Thus, it was proposed that there is a possible interplay between IGF-1 induced activation of PI3K/Akt/ARK5 pathways and cytoskeleton rearrangement ${ }^{43}$. Another study done by Shi et al. showed that suppression of ARK5 could inhibit the F-actin polymerization stimulated by EGF, further elucidating the importance of ARK5 in EGFinduced cofilin recycling and actin polymerization ${ }^{44}$. 
Table 1: The effects of ARK5 in the pathogenesis of several cancer types

\begin{tabular}{|c|c|c|c|}
\hline $\begin{array}{l}\text { Pathways /Pro- } \\
\text { cess Affected }\end{array}$ & Cancer Type & Effects of ARK5 & Reference \\
\hline \multirow[t]{2}{*}{$\begin{array}{l}\text { Cytoskeleton } \\
\text { rearrangement }\end{array}$} & Glioma & $\begin{array}{l}\text { ARK5 regulates cytoskeleton rearrangement (IGF-1- } \\
\text { induced activation of LIMK1 and cofilin). }\end{array}$ & 43 \\
\hline & NSCLC & $\begin{array}{l}\text { Knockdown of ARK5 inhibits EGF-induced F-actin } \\
\text { polymerization. }\end{array}$ & 44 \\
\hline \multirow[t]{6}{*}{ EMT } & Gastric & $\begin{array}{l}\text { Knockdown of ARK5 upregulated E-cadherin and } \\
\text { downregulated Slug, SIP1, and vimentin. }\end{array}$ & 32 \\
\hline & $\mathrm{HCC}$ & $\begin{array}{l}\text { ARK5 stimulated EMT, and ARK5 suppression re- } \\
\text { stored E-cadherin and vimentin expression. }\end{array}$ & 46 \\
\hline & HCC & Knockdown of ARK5 reverse the process of EMT. & 47 \\
\hline & HNSCC & $\begin{array}{l}\text { ARK5 is involved in the invasion and EMT induction } \\
\text { of HNSCC. However, altered ARK5 expression did not } \\
\text { change the cell morphology or the expression of EMT- } \\
\text { related molecules including E-cadherin, N-cadherin, } \\
\text { vimentin, SNAI1, and SNAI2. }\end{array}$ & 48 \\
\hline & NPC & $\begin{array}{l}\text { Knockdown of ARK5 suppressed EMT and reduces N- } \\
\text { cadherin. }\end{array}$ & 49 \\
\hline & Ovarian & $\begin{array}{l}\text { ARK5 overexpression stimulates EMT, downregulates } \\
\text { the epithelial markers and upregulates the mesenchy- } \\
\text { mal expression. }\end{array}$ & 48 \\
\hline \multirow[t]{5}{*}{ MMPs } & Breast & Increased MMP activity. & 50 \\
\hline & Glioma & Increased MMP activity. & 43 \\
\hline & NSCLC & $\begin{array}{l}\text { Knockdown of ARK5 inhibits the activation of MMP- } 2 \\
\text { and MMP-9. }\end{array}$ & 44 \\
\hline & NSCLC & $\begin{array}{l}\text { Knockdown of ARK5 inhibits the activation of MMP-2, } \\
\text { MMP-9 and its transcription regulator (NF-kB). }\end{array}$ & 51 \\
\hline & NPC & $\begin{array}{l}\text { Knockdown of ARK } 5 \text { reduces MMP-2, MMP-9 and its } \\
\text { regulatory factor MT1-MMP. }\end{array}$ & 52 \\
\hline \multirow[t]{3}{*}{ mTOR } & Gastric & $\begin{array}{l}\text { Knockdown of ARK5 downregulated the } \\
\text { mTOR/p70S6k signals. }\end{array}$ & 32 \\
\hline & Glioma & Regulates m-TOR phosphorylation induced by IGF-1 & 43 \\
\hline & NSCLC & $\begin{array}{l}\text { Phosphorylation of m-TOR and induced the phospho- } \\
\text { rylation of two mTOR downstream (p70S6K1 and } 4 \mathrm{E}- \\
\text { binding protein } 1 \text { ( } 4 \mathrm{E}-\mathrm{BP} 1) \text { ) }\end{array}$ & 44 \\
\hline \multirow[t]{2}{*}{ PI3K-Akt } & Breast & $\begin{array}{l}\text { PI3K/Akt/ARK5 pathways activity increased the inva- } \\
\text { siveness of MDA-MB-231 }\end{array}$ & 53 \\
\hline & Colorectal & $\begin{array}{l}\text { Invasion activity was further increased by Akt expres- } \\
\text { sion and decreased by PI-3K inhibitor LY294002 treat- } \\
\text { ment }\end{array}$ & 54 \\
\hline
\end{tabular}

HCC: Hepatocellular carcinoma; HNSCC: Head and neck squamous cellcarcinoma; NPC: Nasopharyngealcancer; NSCLC: Non-small cell lungcarcinoma 


\section{THE ROLE OF ARK5 IN EMT REGULATION}

EMT is known to trigger cancer metastasis, in which epithelial cells gain mesenchymal features that induce tumor invasion and metastasis. Epithelial cells are identified by various characteristics, such as tight connections between the cells, polarized dissemination of multiple organelles and cytoskeleton components, immotile relative to their surroundings, and expressed several epithelial markers such as E-cadherin and $\alpha$-catenin. In contrast, during the EMT process, cells gain mesenchymal properties, for examples, they loose connections between the cells, no polarization of organelles and cytoskeleton component, gain invasive features, and express mesenchymal markers, such as $\mathrm{N}$-cadherin, vimentin, $\beta$-catenin, $\alpha$-SMA, SNAI1, TWIST, TGFB1, ZEB1, and TGFB2 ${ }^{55}$. During EMT, numerous regulatory pathways are altered at multiple levels. The alterations are mainly observed in the transcription and translation process, including the expression of non-coding RNAs, altered splicing and protein stability ${ }^{56}$.

Numerous studies showed that EMT was affected by ARK5 in multiple ways. A study done by Zhang et al. demonstrated that ARK5 downregulates the epithelial markers (E-cadherin) and upregulates the mesenchymal markers (B-catenin, fibronectin, vimentin, a-SMA, SNAI1, TWIST, TGFB1, ZEB1), thus, inducing $\mathrm{EMT}^{51}$. Consistent with the previous findings, $\mathrm{Xu}$ et al. and Chen et al. found that ARK5 suppression can upregulate E-cadherin and downregulate vimentin ${ }^{32,46}$. Xu et al. noted that EMT induced by overexpression of ARK5 was responsible for the development of doxorubicin resistance in HCC cell lines, and another study by Ye et al. showed that suppression of ARK5 could reverse the EMT process ${ }^{46,47}$. Knockdown of ARK5 expression was associated with reduced invasion and metastasis of GC cell, further confirming the role of EMT in tumor invasion and metastasis $^{32}$.

Similarly, Obayashi et al. also concluded that ARK5 was involved in EMT induction and invasion in HNSCC. Interestingly, the results of the study also indicated that ARK5 itself was incapable of inducing EMT as the alterations in ARK5 expression did not affect the cell morphology or the expression level of E-Cadherin, N-Cadherin, vimentin, SNAI1, and SNAI2 ${ }^{48}$. According to these findings, perhaps ARK5 and EMT related markers are both upregulated during EMT, which in turn induces tumor invasion.

\section{ROLE OF ARK5 IN MMPS ACTIVATION}

Tumor invasion in numerous cancers is also induced by the degradation of extracellular matrix and basement membrane by MMPs. MMPs comprises of more than 20 members of zinc-dependent neutral endopeptidases, and amongst them, numerous studies identified that MMP-2 and MMP- 9 are associated with tumor invasiveness. These MMPs should be activated before they could induce extracellular matrix degradation. In addition, MT1-MMP is known to be involved in the process ${ }^{57}$.

Several studies have observed an association between ARK5 expression and MMP activation ${ }^{29,43}$. Suzuki et al. was the first to demonstrate that transfection with Ca-Akt1 or exposure to IGF-1 is associated with an increase in MMP2 and MMP9 level and upregulation of MT1-MMP, potentially confirming the critical role of PI3K-Akt pathway in the activation of MMPs regulated by IGF-1. MT1-MMP upregulation is attributed to increased ARK5 levels, which in turn stimulates MMP2 and MMP9 secretion. These findings indicate that ARK5 probably modulates MT1-MMP expression at the translational level ${ }^{29}$.

Another study done by Chen et al. showed a reduction in the level of the active form of NF-kB (p-p65) in the nucleus of siNUAK1 cells, which are treated with TNF- $\alpha$ before the experiment ${ }^{58}$. NF-kB is a ubiquitous transcription factor and was recognized as a critical regulator in malignant transformation involving MMP upregulation ${ }^{59}$. From these findings, we could assume that ARK5 might also serve as an essential factor in NF-kB activation, which in turn triggers MMP expression.

\section{EPIGENETICS REGULATION OF ARK5 EXPRESSION}

MicroRNA plays an important role in carcinogenesis. Some microRNAs are reported to have tumorsuppressor or oncogene activity, and influence tumor cell survival, proliferation, apoptosis, invasion, and metastasis in various types of human cancers. The expression of microRNAs was found to be dysregulated in most cancer and commonly interact with other genes and proteins, including ARK5 ${ }^{60}$.

Several studies have found that the expression of numerous microRNAs could downregulate ARK5 expression in numerous cancer cell types, which inhibited tumor invasion and progression. Currently, there are five microRNAs, including miR-96, miR145, miR-203, miR-204, and miR-211, which can inhibit ARK5 expression in vitro. Additionally, it is 

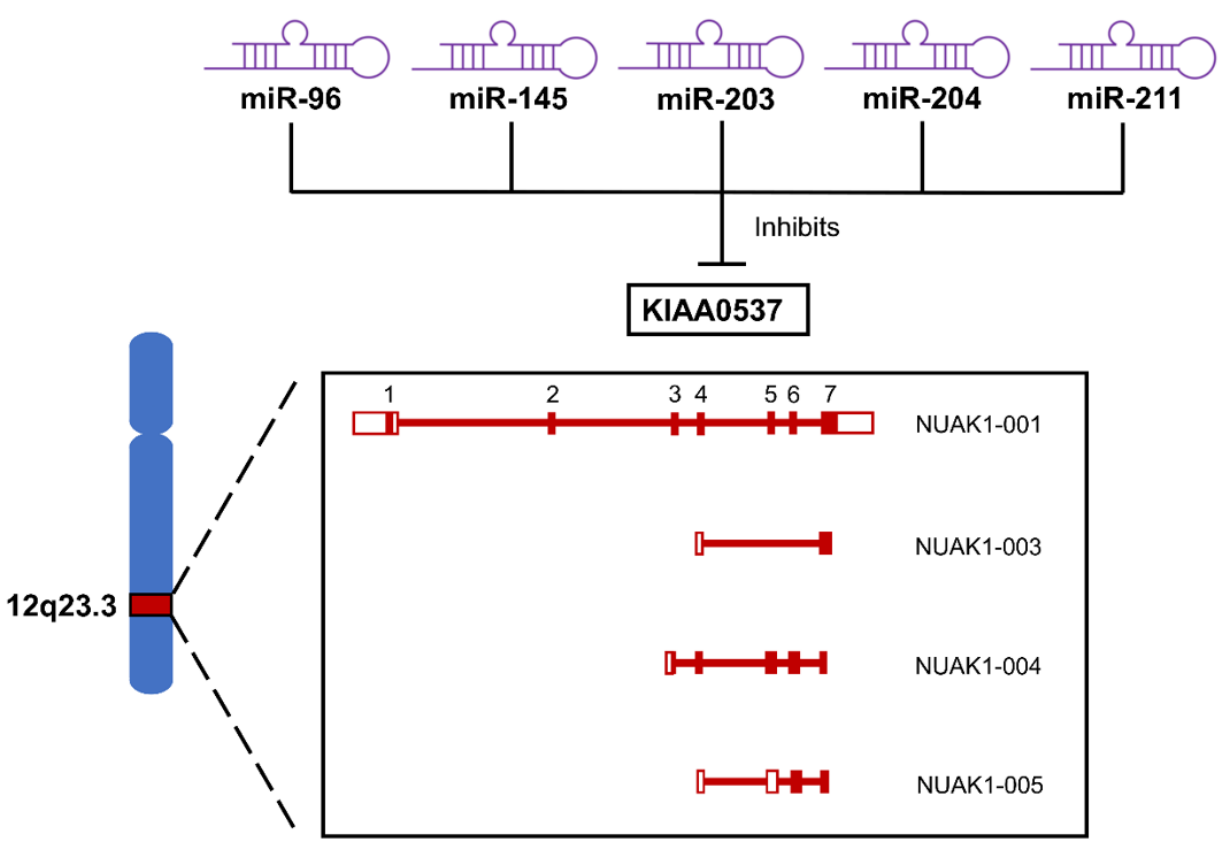

Figure 2: MicroRNAs associated with ARK5 down-regulation. Human ARK5 gene (KIAA0537) is located on chromosome 12q23.3 and encodesa 6828-bp mRNA with four splice variants. Recent studies have identified several microRNAs which influence ARK5 expression. Currently, there are five microRNAs (miR-96, miR-145, miR-203, miR-204, and miR-211) which could down-regulate ARK5 expression in vitro.

found that the expression of these microRNAs is often decreased in various cancer cell lines, which leads to the activation of numerous pathways that induce tumor invasion and progression ${ }^{44,48,61-63}$.

Bell et al. demonstrated that miR-211 directly target ARK5, causing its down-regulation, and thus, leads to reduced invasion activity in melanoma ${ }^{61}$. The findings of this study also suggested that ARK5 is a downstream target of MITF via miR-211. Another study by Xiong et al. found that miR-145 directly targets ARK5, suppressing PI3k-Akt signaling and MMP expression in intrahepatic cholangiocarcinoma cell ${ }^{63}$. Similarly, Obayashi et al. also showed that miR-203 could downregulate ARK5 and suppressed invasion and EMT in HNSCC ${ }^{48}$. Furthermore, the results of several studies have revealed that miR-96 and miR204 could down-regulate ARK5 expression by targeting its 3' UTR ${ }^{44,63}$. In contrast, Zhang et al. found that ARK5 could down-regulate miR-1181 expression, and thus, leading to increased EMT in ovarian cancer cell lines ${ }^{51}$.

Over-expression of ARK5 in cancer cell lines can also be stimulated by c-MAF and MAFB of the LargeMAF family. It was first noted in the study done by Suzuki et al. that c-MAF, MAFB, and ARK5 mRNAs are often expressed together in multiple myeloma cell lines ${ }^{64}$. This observation leads to a hypothesis that ARK5 gene transcription could be affected by LargeMAF family, considering that c-MAF and MAFB are known to stimulate gene transcription through the interaction with MAF-recognition element (MARE) sequences on the promoter region of the gene ${ }^{52}$.

An earlier study done by Motohashi et al. indicated that TGCTGAC is regarded as the core sequence of MARE and that the 5'-side thymidine is indispensable for the interaction between c-MAF/MAFB with $M_{A R E}{ }^{53}$. Suzuki et al. found that the sequence of ARK5 promoter encompasses two MARE core sequences mentioned in the previous study ${ }^{64}$. It is also observed that the expression of ARK5 gene induced by increased expression of c-MAF and MAFB was significantly lower when either MARE sequences was mutated. Together, these findings demonstrate that ARK5 gene transcription is influenced by the interaction of c-MAF and MAFB with both MARE core sequence present in the ARK5 promoter ${ }^{64}$.

\section{CONCLUSIONS}

Early detection of cancer is vital to improve the survival rates of cancer patients, and ARK5 expression is 
currently deemed as a promising biomarker of cancer development and progression. Based on the latest evidences, ARK5 might be a master regulator of cancer progression and metastasis due to its involvement in several important cancer pathways. Additionally, ARK5 expression was also affected by several microRNAs, which could down-regulate ARK5 expression in vitro, and thus, might be useful in therapeutic application. Further studies are needed to fully elucidate the function of ARK5 and to develop a strategy to inhibit ARK5 expression, which could serve as a novel target for cancer therapies in the future.

\section{ABBREVIATIONS}

AMPK: AMP-activated protein kinase

ARK5: AMPK-related kinase 5

CaMKKb: $\mathrm{Ca}^{2+} /$ Calmodullin-dependent protein kinase kinase $\mathrm{b}$

EMT: Epithelial mesenchymal transformation

GC: Gastric cancer

HCC: Hepatocellular carcinoma

HNSCC: Head and neck squamous cell carcinoma

IGF1: Insulin-like growth factor 1

LKB1: Liver kinase b 1

MARE: MAF-recognition element

MMP: Matrix metalloproteinase

mTOR: Mammalian target of Rapamycin

NCD: Noncommunicable disease

NPC: Nasopharyngeal carcinoma

NSCLC: Non-small cell lung carcinoma

NUAK1: Novel kinase family 1

Tak1: Transforming growth factor $b$ kinase 1

\section{COMPETING INTERESTS}

The authors declare no conflicts of interest.

\section{AUTHORS' CONTRIBUTIONS}

All authors contributed to the drafting of this manuscript. AB and CT searched, obtained and summarized the data. $\mathrm{AB}$ and $\mathrm{AS}$ reviewed and edited the first draft of the manuscript. All authors reviewed, commented and approved the final draft of the manuscript.

\section{ACKNOWLEDGMENTS}

The authors would like to acknowledge School of Medicine and Health Sciences, Atma Jaya Catholic University of Indonesia for all the support for this research project.

\section{REFERENCES}

1. WHO | The data repository: World Health Organization; 2016 [Available from: http://www.who.int/gho/database/en /.; 2016.

2. Bray F, Jemal A, Grey N, Ferlay J, Forman D. Global cancer transitions according to the Human Development Index (2008-2030): a population-based study. The Lancet Oncology. 2012;13(8):790-801. PMID: 22658655. Available from: 10.1016/S1470-2045(12)70211-5.

3. Mathers CD, Loncar D. Projections of global mortality and burden of disease from 2002 to 2030. PLoS Medicine. 2006;3(11):e442. PMID: 17132052. Available from: 10.1371/ journal.pmed.0030442.

4. Bray F. Transitions in human development and the global cancer burden. World cancer report. 2014;p. 54-68.

5. Bray F, Ferlay J, Soerjomataram I, Siegel RL, Torre LA, Jemal A. Global cancer statistics 2018: GLOBOCAN estimates of incidence and mortality worldwide for 36 cancers in 185 countries. CA: a Cancer Journal for Clinicians. 2018;68(6):394-424. PMID: 30207593. Available from: 10.3322/caac.21492.

6. Sawyers $\mathrm{CL}$. The cancer biomarker problem. Nature. 2008;452(7187):548-52. PMID: 18385728. Available from: 10.1038 /nature06913.

7. Tarro G, Perna A, Esposito C. Early diagnosis of lung cancer by detection of tumor liberated protein. Journal of Cellular Physiology. 2005;203(1):1-5. PMID: 15389637. Available from: 10.1002/jcp. 20195.

8. Wu L, Qu X. Cancer biomarker detection: recent achievements and challenges. Chemical Society Reviews. 2015;44(10):296397. PMID: 25739971. Available from: 10.1039/C4CS00370E.

9. Han F, Li CF, Cai Z, Zhang X, Jin G, Zhang WN, et al. The critical role of AMPK in driving Akt activation under stress, tumorigenesis and drug resistance. Nature Communications. 2018;9(1):4728. PMID: 30413706. Available from: 10.1038/ s41467-018-07188-9.

10. Bright NJ, Thornton C, Carling D. The regulation and function of mammalian AMPK-related kinases. Acta Physiologica (Oxford, England). 2009;196(1):15-26. PMID: 19245655. Available from: 10.1111/j.1748-1716.2009.01971.x.

11. Williams T, Brenman JE. LKB1 and AMPK in cell polarity and division. Trends in Cell Biology. 2008;18(4):193-8. PMID: 18314332. Available from: 10.1016/j.tcb.2008.01.008.

12. Hardie DG, Carling D, Carlson M. The AMP-activated/SNF1 protein kinase subfamily: metabolic sensors of the eukaryotic cell? Annual Review of Biochemistry. 1998;67(1):821-55. PMID: 9759505. Available from: 10.1146/annurev.biochem.67. 1.821.

13. Marsin AS, Bouzin C, Bertrand L, Hue L. The stimulation of glycolysis by hypoxia in activated monocytes is mediated by AMP-activated protein kinase and inducible 6phosphofructo-2-kinase. The Journal of Biological Chemistry. 2002;277(34):30778-83. PMID: 12065600. Available from: 10.1074/jbc.M205213200.

14. Gao G, Widmer J, Stapleton D, Teh T, Cox T, Kemp BE, et al. Catalytic subunits of the porcine and rat $5^{\prime}$-AMP-activated protein kinase are members of the SNF1 protein kinase family. Biochimica et Biophysica Acta. 1995;1266(1):73-82. PMID: 7718624. Available from: 10.1016/0167-4889(94)00222-Z.

15. Abbud W, Habinowski S, Zhang JZ, Kendrew J, Elkairi FS, Kemp BE, et al. Stimulation of AMP-activated protein kinase (AMPK) is associated with enhancement of Glut1-mediated glucose transport. Archives of Biochemistry and Biophysics. 2000;380(2):347-52. PMID: 10933890. Available from: 10. 1006/abbi.2000.1935.

16. Suzuki A, Kusakai G, Kishimoto A, Lu J, Ogura T, Lavin MF, et al. Identification of a novel protein kinase mediating Akt survival signaling to the ATM protein. The Journal of Biological Chemistry. 2003;278(1):48-53. PMID: 12409306. Available from: 10.1074/jbc.M206025200.

17. Inazuka F, Esumi H. NUAK1 (NUAK family, SNF1-like kinase, 1). Atlas of Genetics and Cytogenetics in Oncology and Haematology. 2014;18(11):834-7. 
18. Nagase T, Ishikawa K, Miyajima N, Tanaka A, Kotani H, Nomura $\mathrm{N}$, et al. Prediction of the coding sequences of unidentified human genes. IX. The complete sequences of 100 new CDNA clones from brain which can code for large proteins in vitro. DNA Research. 1998;5(1):31-9. PMID: 9628581. Available from: 10.1093/dnares/5.1.31.

19. Palma M, Riffo EN, Suganuma T, Washburn MP, Workman JL, Pincheira $\mathrm{R}$, et al. Identification of a nuclear localization signal and importin beta members mediating NUAK1 nuclear import inhibited by oxidative stress. Journal of Cellular Biochemistry. 2019;120(9):16088-107. PMID: 31090959. Available from: $10.1002 / j c b .28890$.

20. Manning G, Whyte DB, Martinez R, Hunter $T$, Sudarsanam $S$. The protein kinase complement of the human genome. Science. 2002;298(5600):1912-34. PMID: 12471243. Available from: $10.1126 /$ science. 1075762 .

21. Lizcano JM, Göransson $O$, Toth $R$, Deak M, Morrice NA, Boudeau J, et al. LKB1 is a master kinase that activates 13 kinases of the AMPK subfamily, including MARK/PAR-1. The EMBO Journal. 2004;23(4):833-43. PMID: 14976552. Available from: 10.1038/sj.emboj.7600110

22. Suzuki A, Kusakai G, Kishimoto A, Lu J, Ogura T, Esumi H. ARK5 suppresses the cell death induced by nutrient starvation and death receptors via inhibition of caspase 8 activation, but not by chemotherapeutic agents or UV irradiation. Oncogene. 2003;22(40):6177-82. PMID: 13679856. Available from: 10.1038/sj.onc.1206899.

23. Suzuki A, Ogura T, Esumi H. NDR2 acts as the upstream kinase of ARK5 during insulin-like growth factor-1 signaling. The Journal of Biological Chemistry. 2006;281(20):13915-21. PMID: 16488889. Available from: 10.1074/jbc.M511354200.

24. Kusakai G, Suzuki A, Ogura T, Kaminishi M, Esumi H. Strong association of ARK5 with tumor invasion and metastasis. Journal of Experimental \& Clinical Cancer Research. 2004;23(2):263-8. PMID: 15354411.

25. Morito N, Yoh K, Fujioka Y, Nakano T, Shimohata H, Hashimoto $\mathrm{Y}$, et al. Overexpression of c-Maf contributes to T-cell lymphoma in both mice and human. Cancer Research. 2006;66(2):812-9. PMID: 16424013. Available from: 10.1158/ 0008-5472.CAN-05-2154.

26. Liu L, Ulbrich J, Müller J, Wüstefeld T, Aeberhard L, Kress TR et al. Deregulated MYC expression induces dependence upon AMPK-related kinase 5. Nature. 2012;483(7391):608-12. PMID: 22460906. Available from: 10.1038/nature10927.

27. Cui J, Yu Y, Lu GF, Liu C, Liu X, Xu YX, et al. Overexpression of ARK5 is associated with poor prognosis in hepatocellular carcinoma. Tumour Biology. 2013;34(3):1913-8. PMID: 23516026. Available from: 10.1007/s13277-013-0735-x.

28. Datta SR, Brunet A, Greenberg ME. Cellular survival: a play in three Akts. Genes \& Development. 1999;13(22):2905-27. PMID: 10579998. Available from: 10.1101/gad.13.22.2905.

29. Suzuki A, Lu J, Kusakai G, Kishimoto A, Ogura T, Esumi H. ARK5 is a tumor invasion-associated factor downstream of Akt signaling. Molecular and Cellular Biology. 2004;24(8):3526-35. PMID: 15060171. Available from: 10.1128/MCB.24.8.35263535.2004.

30. Lawlor MA, Alessi DR. PKB/Akt: a key mediator of cell proliferation, survival and insulin responses? Journal of Cell Science. 2001;114(Pt 16):2903-10. PMID: 11686294.

31. Cheng K, Hao M. Metformin Inhibits TGF- $\beta$ 1-Induced Epithelial-to-Mesenchymal Transition via PKM2 RelativemTOR/p70s6k Signaling Pathway in Cervical Carcinoma Cells. International Journal of Molecular Sciences. 2016;17(12):2000. PMID: 27916907. Available from: 10.3390/ijms17122000.

32. Chen D, Liu G, Xu N, You X, Zhou H, Zhao X, et al. Knockdown of ARK5 Expression Suppresses Invasion and Metastasis of Gastric Cancer. Cellular Physiology and Biochemistry. 2017;42(3):1025-36. PMID: 28662499. Available from: $10.1159 / 000478685$.

33. Esumi H, Izuishi K, Kato K, Hashimoto K, Kurashima Y, Kishimoto $A$, et al. Hypoxia and nitric oxide treatment confer tolerance to glucose starvation in a 5'-AMP-activated protein kinase-dependent manner. The Journal of Biological Chemistry. 2002;277(36):32791-8. PMID: 12091379. Available from: 10.1074/jbc.M112270200.

34. Izuishi K, Kato K, Ogura T, Kinoshita T, Esumi H. Remarkable tolerance of tumor cells to nutrient deprivation: possible new biochemical target for cancer therapy. Cancer Research. 2000;60(21):6201-7. PMID: 11085546.

35. Suzuki A, Kusakai G, Kishimoto A, Shimojo Y, Miyamoto $S$, Ogura T, et al. Regulation of caspase- 6 and FLIP by the AMPK family member ARK5. Oncogene. 2004;23(42):7067-75. PMID: 15273717. Available from: 10.1038/sj.onc. 1207963.

36. Stein SC, Woods A, Jones NA, Davison MD, Carling D. The regulation of AMP-activated protein kinase by phosphorylation. The Biochemical Journal. 2000;345(Pt 3):437-43. PMID: 10642499. Available from: 10.1042/bj3450437.

37. Hawley SA, Boudeau J, Reid JL, Mustard KJ, Udd L, Mäkelä TP, et al. Complexes between the LKB1 tumor suppressor, STRAD alpha/beta and $\mathrm{MO} 25$ alpha/beta are upstream kinases in the AMP-activated protein kinase cascade. Journal of Biology. 2003;2(4):28. PMID: 14511394. Available from: 10.1186/14754924-2-28.

38. Hawley SA, Pan DA, Mustard KJ, Ross L, Bain J, Edelman AM, et al. Calmodulin-dependent protein kinase kinase-beta is an alternative upstream kinase for AMP-activated protein kinase. Cell Metabolism. 2005;2(1):9-19. PMID: 16054095. Available from: 10.1016/j.cmet.2005.05.009.

39. Sun X, Gao L, Chien HY, Li WC, Zhao J. The regulation and function of the NUAK family. Journal of Molecular Endocrinology. 2013;51(2):15-22. PMID: 23873311. Available from: 10.1530/JME-13-0063.

40. Hou X, Liu JE, Liu W, Liu CY, Liu ZY, Sun ZY. A new role of NUAK1: directly phosphorylating $\mathrm{p} 53$ and regulating cell proliferation. Oncogene. 2011;30(26):2933-42. PMID: 21317932. Available from: 10.1038/onc.2011.19.

41. Humbert N, Navaratnam N, Augert A, Costa MD, Martien $S$, Wang J, et al. Regulation of ploidy and senescence by the AMPK-related kinase NUAK1. The EMBO Journal. 2010;29(2):376-86. PMID: 19927127. Available from: 10.1038/ emboj.2009.342.

42. Wang Y, Sheng Q, Spillman MA, Behbakht K, Gu H. Gab2 regulates the migratory behaviors and $\mathrm{E}$-cadherin expression via activation of the PI3K pathway in ovarian cancer cells. Oncogene. 2012;31(20):2512-20. PMID: 21996746. Available from: 10.1038/onc.2011.435.

43. Lu S, Niu N, Guo H, Tang J, Guo W, Liu Z, et al. ARK5 promotes glioma cell invasion, and its elevated expression is correlated with poor clinical outcome. European Journal of Cancer (Oxford, England). 2013;49(3):752-63. PMID: 23063350. Available from: 10.1016/j.ejca.2012.09.018.

44. Shi L, Zhang B, Sun X, Lu S, Liu Z, Liu Y, et al. MiR-204 inhibits human NSCLC metastasis through suppression of NUAK1. British Journal of Cancer. 2014;111(12):2316-27. PMID: 25412236. Available from: 10.1038/bjc.2014.580.

45. Ghosh M, Song X, Mouneimne G, Sidani M, Lawrence DS, Condeelis JS. Cofilin promotes actin polymerization and defines the direction of cell motility. Science. 2004;304(5671):743-6. PMID: 15118165. Available from: 10.1126/science.1094561.

46. Xu T, Zhang J, Chen W, Pan S, Zhi X, Wen L, et al. ARK5 promotes doxorubicin resistance in hepatocellular carcinoma via epithelial-mesenchymal transition. Cancer Letters. 2016;377(2):140-8. PMID: 27126361. Available from: 10.1016/ j.canlet.2016.04.026.

47. Ye Z, Chen X, Chen X. ARK5 promotes invasion and migration in hepatocellular carcinoma cells by regulating epithelialmesenchymal transition. Oncology Letters. 2018;15(2):15116. PMID: 29434843.

48. Obayashi M, Yoshida M, Tsunematsu T, Ogawa I, Sasahira T, Kuniyasu $\mathrm{H}$, et al. microRNA-203 suppresses invasion and epithelial-mesenchymal transition induction via targeting NUAK1 in head and neck cancer. Oncotarget. 2016;7(7):822339. PMID: 26882562. Available from: 10.18632/oncotarget. 
6972.

49. Lan $X$, Liu X. LncRNA SNHG1 functions as a ceRNA to antagonize the effect of miR-145a-5p on the down-regulation of NUAK1 in nasopharyngeal carcinoma cell; 2018.

50. Chang XZ, Yu J, Liu HY, Dong RH, Cao XC. ARK5 is associated with the invasive and metastatic potential of human breast cancer cells. Journal of Cancer Research and Clinical Oncology. 2012;138(2):247-54. PMID: 22105900. Available from: 10.1007/s00432-011-1102-1.

51. Zhang HY, Li JH, Li G, Wang SR. Activation of ARK5/miR1181/HOXA10 axis promotes epithelial-mesenchymal transition in ovarian cancer. Oncology Reports. 2015;34(3):1193202. PMID: 26151663. Available from: 10.3892/or.2015.4113.

52. Kataoka K, Fujiwara KT, Noda M, Nishizawa M. MafB, a new Maf family transcription activator that can associate with Maf and Fos but not with Jun. Molecular and Cellular Biology. 1994;14(11):7581-91. PMID: 7935473. Available from: 10 1128/MCB.14.11.7581.

53. Motohashi $H$, Shavit JA, Igarashi $K$, Yamamoto $M$, Engel JD. The world according to Maf. Nucleic Acids Research. 1997;25(15):2953-9. PMID: 9224592. Available from: 10.1093/ nar/25.15.2953.

54. Kusakai G, Suzuki A, Ogura T, Miyamoto S, Ochiai A, Kaminishi $M$, et al. ARK5 expression in colorectal cancer and its implications for tumor progression. American Journal of Pathology. 2004;164(3):987-95. PMID: 14982852. Available from: 10.1016/S0002-9440(10)63186-0.

55. Larue L, Bellacosa A. Epithelial-mesenchymal transition in development and cancer: role of phosphatidylinositol 3' kinase/AKT pathways. Oncogene. 2005;24(50):7443-54. PMID: 16288291. Available from: 10.1038/sj.onc.1209091.

56. Chang CJ, Chao CH, Xia W, Yang JY, Xiong Y, Li CW, et al. p53 regulates epithelial-mesenchymal transition and stem cell properties through modulating miRNAs. Nature Cell Biology. 2011;13(3):317-23. PMID: 21336307. Available from: $10.1038 /$ ncb2173.

57. Cavdar Z, Canda AE, Terzi C, Sarioglu S, Fuzun M, Oktay G. Role of gelatinases (matrix metalloproteinases 2 and 9), vascular endothelial growth factor and endostatin on clinico- pathological behaviour of rectal cancer. Colorectal Disease. 2011;13(2):154-60. PMID: 19888958. Available from: 10.1111/ j.1463-1318.2009.02105.x.

58. Chen P, Li K, Liang Y, Li L, Zhu X. High NUAK1 expression correlates with poor prognosis and involved in NSCLC cells migration and invasion. Experimental Lung Research. 2013;39(1):917. PMID: 23215946. Available from: 10.3109/01902148.2012. 744115.

59. Felx M, Guyot MC, Isler M, Turcotte RE, Doyon J, Khatib AM, et al. Endothelin-1 (ET-1) promotes MMP-2 and MMP-9 induction involving the transcription factor NF-kappaB in human osteosarcoma. Clinical Science (London, England). 2006;110(6):645-54. PMID: 16417466. Available from: 10 $1042 / C S 20050286$

60. Garzon R, Calin GA, Croce CM. MicroRNAs in Cancer. Annual Review of Medicine. 2009;60(1):167-79. PMID: 19630570. Available from: 10.1146/annurev.med.59.053006.104707.

61. Bell RE, Khaled M, Netanely D, Schubert S, Golan T, Buxbaum A, et al. Transcription factor/microRNA axis blocks melanoma invasion program by miR-211 targeting NUAK1. The Journal of Investigative Dermatology. 2014;134(2):441-51. PMID: 23934065. Available from: 10.1038/jid.2013.340.

62. Huang $X, L v$ W, Zhang JH, Lu DL. miR-96 functions as a tumor suppressor gene by targeting NUAK1 in pancreatic cancer. International Journal of Molecular Medicine. 2014;34(6):1599605. PMID: 25242509. Available from: 10.3892/ijmm.2014. 1940.

63. Xiong $X$, Sun D, Chai H, Shan W, Yu Y, Pu L, et al. MiR-145 functions as a tumor suppressor targeting NUAK1 in human intrahepatic cholangiocarcinoma. Biochemical and Biophysical Research Communications. 2015;465(2):262-9. PMID: 26255969. Available from: 10.1016/j.bbrc.2015.08.013.

64. Suzuki A, lida S, Kato-Uranishi M, Tajima E, Zhan F, Hanamura I, et al. ARK5 is transcriptionally regulated by the Large-MAF family and mediates IGF-1-induced cell invasion in multiple myeloma: ARK5 as a new molecular determinant of malignant multiple myeloma. Oncogene. 2005;24(46):6936-44. PMID: 16044163. Available from: 10.1038/sj.onc.1208844. 